\title{
AISLAMIENTO DE Candida Albicans EN LA CAVIDAD ORAL EN LOS NIÑOS EN EDAD ESCOLAR DE LAZONAURBANADELMUNICIPIO DE CHAGUANÍ - CUNDINAMARCA Y VARIABLES ASOCIADAS A SINTOMATOLOGÍA
}

\section{ISOLATION OF Candida Albicans IN THE ORAL CAVITY IN CHILDREN OF SCHOOL AGE IN THE URBAN AREA OF THE MUNICIPALITY OF CHAGUANÍ - CUNDINAMARCA AND VARIABLES ASSOCIATED WITH SYMPTOMS}

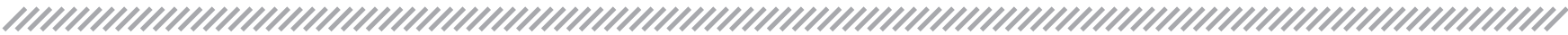
AUTORES: Guatibonza Andrea Milena ${ }^{1}$, Giraldo Julio Cesar', Gutiérrez Elizabeth ${ }^{3}$, Ricaurte Laura Alejandra
\end{abstract}

1)

\section{RESUMEN}

La candidiasis oral se ha considerado como una de las infecciones más frecuentes en la cavidad bucal, la cual es atribuida a Candida albicans en la mayoría de los casos y en los niños generalmente cursa de manera asintomática.

OBJETIVO: Identificar las posibles variables asociadas a la sintomatología correspondiente a candidiasis oral presentada en niños en edad pre- escolar y escolar.

METODOLOGÍA: Se incluyeron 99 muestras de niños en edad pre-escolar y escolar cuyos padres asintieron participar voluntariamente con la firma de un asentimiento informado y el diligenciamiento de una encuesta epidemiológica, el aislamiento y caracterización bioquímica se realizó empleando las técnicas de siembra en Agar OGY, Microcultivo en agar harina de maíz para la formación de Clamidosporas, técnica de producción de tubo germinal en suero humano y prueba de urea. Para la valoración de sensibilidad y/o resistencia, se emplearon diez tipos de enjuagues bucales comerciales impregnados en sensidiscos. Finalmente se realizó el análisis estadístico utilizando el programa SPSSv2.0 en el cual se calculó las posibles asociaciones con las variables evaluadas.

RESULTADOS: Arrojaron una prevalencia del 67,7\%(67/99) para Candida albicas, de los cuales el $38.8 \%(26 / 67)$ y $43,2 \%(29 / 67)$ correspondió al género masculino y femenino respectivamente, cuyas edades oscilaron de cero a doce años. La sensibilidad como la resistencia para los enjuagues evaluados fue del 50\% respectivamente. La variable que se identificó con posible asociación con sintomatología, fue dolor en las encías, valor de $\mathrm{P}=0,005$. Otras afecciones de la cavidad oral como la caries dental, puede estar relacionada con la presencia de Candida albicans.

PALABRAS CLAVE: Candidiasis oral, Candida albicans, sintomatología, caracterización bioquímica, prueba de sensibilidad y/o resistencia.

\section{ABSTRACT}

Thrush is considered one of the most common infections in the oral cavity, which is attributed to Candida albicans in most cases in children and usually patients are asymptomatic.

OBJECTIVE: To identify the possible variables associated with the corresponding oral candidiasis presented in school and preschool age symptoms.

METHODS: 99 samples of children in pre-school children whose parents were included and nodded school voluntarily participate by signing an informed consent and filling out an epidemiological survey, isolation and biochemical characterization was done using planting techniques OGY Agar, microculture cornmeal agar for the formation of chlamydospores production technique in human serum germ tube test and urea. For the assessment of sensitivity and / or resistance, impregnated ten types of commercial mouthwashes were used in sensidiscs. Finally the statistical analysis using the program in which SPSSv2.0 possible associations with the variables evaluated was calculated took place.

13 , Estudiante Semillero de Investigacion SIPAMT - Universidad INCCA de Colombia

${ }^{2}$ Lider del grupo de Investigacion GIPAMT - Universidad INCCA de Colombia 
RESULTS: showed a prevalence of $67.7 \%(67 / 99)$ for Candida albicans, of which $38.8 \%$ (26/67) and $43.2 \%$ (29/67) corresponded to male and female respectively, whose ages They ranged from zero to twelve. The sensitivity and resistance to the washes was evaluated 50\% respectively. The variable that is identified with possible association with symptoms, was sore gums, $\mathrm{P}=$ 0.005 . Other conditions of the oral cavity such as dental caries, can be related to the presence of Candida albicans.

KEY WORDS: oral candidiasis, Candida albicans, symptoms, biochemical characterization, test sensitivity and / or resistance.

\section{INTRODUCCIÓN}

La candidiasis es una micosis causada por diversas especies de levadura del género Candida sp, el cual se caracteriza por ser un organismo comensal muy frecuente y que ocasiona un amplio espectro de infecciones en la piel, mucosas y a nivel sistémico (1), las afecciones oportunistas son causadas por la especie Candida albicans, la cual tiene importancia estomatológica, por su frecuencia y variedad clínica, esta afección se encuentra principalmente en personas con distintos tipos de factores predisponentes que facilitan el paso de Candida de comensal a patógeno (2).

La mayoría de las especies de Candida que se aíslan comúnmente de la cavidad oral en los niños, no se consideran patógenas, siempre y cuando el infante no se encuentre expuesto a condiciones de inmunocompromiso o a factores de riesgo como lo son: intubación endotraqueal, catéter venoso central, nutrición parenteral, estancia prolongada en la unidad de cuidados intensivos, antibióticos de amplio espectro, infecciones bacterianas, transfusiones sanguíneas, procedimientos quirúrgicos recientes, infección por el virus de Inmunodeficiencia Humana, trasplante de medula ósea y procesos neoplásicos; estos permiten que los hongos se comporten como oportunistas, causando de esta manera una infección micótica (3).

En la actualidad se ha dado a conocer que la capacidad de adaptación genética y fenotípica de C. albicans, le permite mejorar sus estrategias de supervivencia especialmente en la cavidad oral cuando la respuesta inmune es deficiente y la respuesta de los tejidos es alterada como barrera primaria (4).

Se sabe que la presencia de Candida albicans puede presentarse en cualquier parte del cuerpo, principalmente afectando la zona de las mucosas como cavidad oral, gastrointestinal y vaginal entre las más conocidas; cada una de ellas manifiesta una sintomatología diferente, que en algunos casos el dolor es el más prevalente como hay otros en los que esta pasa de manera desapercibida (5). Sin embargo hay variables con los que la sintomatología pueda estar posiblemente asociada con la presencia de candidiasis.

\section{MATERIALES Y METODOS}

Se realizó un estudio descriptivo de corte transversal con toma única de muestra a 99 participantes de la población infantil del área urbana del municipio de Chaguaní - Cundinamarca en el primer semestre del 2015, cuyos padres asintieron participar voluntariamente, con la firma de un consentimiento informado y el diligenciamiento de una encuesta epidemiológica. Las muestras fueron evaluadas con las siguientes pruebas:

\section{Siembra en Agar OGY}

Cada muestra se sembró a partir del frotis inoculado en Caldo Sabureaud, empleando la técnica de agotamiento para aislamiento de colonias e incubación a $37^{\circ} \mathrm{C}$ por 48 horas.

\section{Coloración de Gram}

Identificadas las colonias, se procedió a realizar la coloración compuesta diferencial de Gram y evaluación por examen microscópico con objetivo de inmersión y lectura doble ciego para la identificación de estructuras levaduriformes y en proceso de gemación.

Técnica de Microcultivo

Identificada la presencia de estructuras levaduriformes, se procedió a realizar la técnica de Microcultivo, para la cual se empleó recuadros de un centímetro de Agar harina de maíz, donde cada muestras se inoculó e incubó en cámara húmeda a $37^{\circ} \mathrm{C}$ durante 24 horas y posteriormente se adicionó azul de Lactofenol y se observó microscópicamente con objetivo 40X.

Formación de tubo germinal

Para esta técnica se implementó con suero humano, el cual se distribuyó en alícuotas de $100 \mu 1$ en tubos Eppendorf en los que se inoculó una fracción de cada una de las muestra y se incubó en baño serológico durante 30 minutos. Posteriormente se procedió a realizar lecturas con objetivo 40X para identificar la presencia de tubo germinal.

Prueba de Urea

Las muestras fueron inoculadas en caldo Urea e incubadas a $37^{\circ} \mathrm{C}$ durante 24 horas, posteriormente se eva- 


\section{luó la producción o no de la enzima ureasa.}

Prueba de sensibilidad y/o resistencia

Se realizó siembra masiva de las muestras en agar OGY, para lo cual se utilizaron diez tipos diferentes de enjuagues bucales comerciales con los que se humedecieron sensidiscos de $4 \mathrm{~mm}$ de diámetro de papel Wattman $\mathrm{N}^{\circ} 1$ marcados respectivamente con el número correspondiente al enjuague utilizado. Se incubó cada muestra a $37^{\circ} \mathrm{C}$ durante 48 horas hasta que se obtuviera el crecimiento de en masa y la formación de los halos de inhibición o no. Finalmente se midió el diámetro de cada uno de estos en las muestras que se presentaron.

\section{RESULTADOS}

Se incluyeron 99 participantes a los cuales se les realizó muestra de frotis bucal y estos mostraron los siguientes resultados:

A partir del proceso de caracterización bioquímica realizadas para las muestras se identificó Candida albicans, resultados que se presenta en la tabla 1.

\section{Tabla 1. Porcentaje de muestras positivas y/o negativas mediante valoración bioquímica}

Prueba tipificación Porcentaje $\quad N^{\circ}$ de Muestras

\begin{tabular}{lcc}
\hline Crecimiento en Agar OGY & $(+) 70,7 \%$ & 70 \\
Coloración compuesta de Gram & $(+) 70,7 \%$ & 70 \\
Microcultivo & $(+) 67,7 \%$ & 67 \\
Tubo germinal & $(+) 67,7 \%$ & 67 \\
Prueba de Urea & $(-) 97 \%$ & 96
\end{tabular}

Se tomaron positivas aquellas muestras que correspondieron con las siguientes características: crecimiento en Agar OGY, producción de Clamidosporas, producción de tubo germinal y Ureasa negativo. Los resultados arrojaron que el $67,7 \%$ (67/99) de las muestras presentaron las características bioquímicas para ser tipificadas como Candida albicans.

\section{Prueba de sensibilidad y/o resistencia}

De acuerdo a la formación de halo de inhibición para los enjuagues comerciales evaluados, se presentó sensibilidad y/o resistencia en el 50\% de las muestras respectivamente.

\section{Distribución por género}

El total de la población participante, se distribuyó por género: 37 niños de los cuales 26 fueron positivos para Candida albicans, 48 niñas y de estas 29 presentaron el agente etiológico, un grupo de 14 muestras de las cuales no se tuvo información de edad, género, entre otros, se les denominó indeterminadas y de estas 12 fueron positivas. De igual manera a los participantes se distribuyeron en cuatro grupos etarios siendo estos: de cero a tres años, de cuatro a seis, de siete a nueve y mayores a diez; En el género masculino se presentó el mayor prevalencia del agente etiológico en el grupo etario de cero a tres siendo del 100\% (6/6). En tanto que para el género femenino la mayor presencia fue en el grupo de diez años o más con valor porcentual del 77,78\% (7/9).

\section{Encuesta epidemiológica}

En el análisis de las variables evaluadas se identificó que las dietas ricas en carbohidratos y el presentar buen hábito de higiene oral se destacan. En cuanto a las variables restantes se presentan los valores porcentuales en el grafico 1.

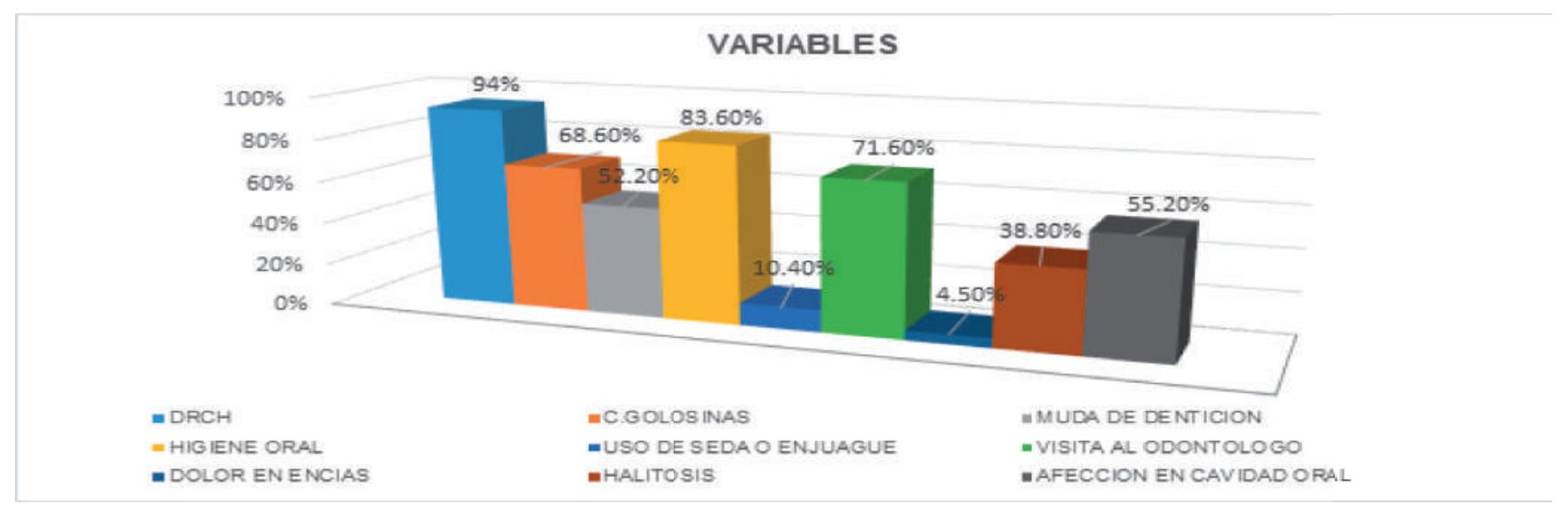

Grafico 1. Valores Porcentuales de las variables asociadas: hábitos de higiene oral, afecciones orales y alimenticios. 


\section{Prevalencia}

Para el análisis estadístico se empeló el programa SPSSv2.0, el cual permitió el cálculo porcentual de la prevalencia, valor de ji cuadrado para identificar la existencia o no de asociaciones de las variables evaluadas y su relación con la presencia de Candida albicans.

Tabla 2. Valores de P calculado y posible asociación con las variables de higiene oral y sintomatología.

Posible asociación de Candidiasis frente a las variables

Número de comidas diarias

Consumo de dietas ricas en Carbohidratos

Lavado de frutas antes del consumirlas

Consumo de golosinas

Muda de dentición

Número de cepillados diarios

Cepillado acompañado de enjuague

Con que

Sangrado de encías

Visita al odontólogo

Ultima Consulta

Tratamiento

Ortodoncia

Dolor en encías

Halitosis

Anomalías
Valor de $P$
0,639
0,664
0,337
0,108
0,378
0,411
0,473
0,324
0,68
0,175
0,37
0,559
0,764
0,018
0,811
0,52

Tabla 3. Sintomatología asociada con la presencia de Candida albicans

A los participantes que se les realizó aislamiento de Candida albicans, se procedió a identificar sintoma- tología y la posible asociación con las variables evaluadas.

\begin{tabular}{lcc} 
SINTOMAS & POSITIVO & PORCENTAJE \\
\hline Presencia de sangrado de encías & 13 & $19,40 \%$ \\
Presencia de dolor en las encías & 3 & $4,47 \%$ \\
Halitosis & 18 & $26,86 \%$ \\
Presencia de placa bacteriana & 5 & $7,46 \%$ \\
Presencia de sarro & 11 & $16,41 \%$ \\
Presencia de caries & 24 & $35,82 \%$ \\
Gingivitis & 2 & $2,98 \%$ \\
Periodontitis & 0 & $0,00 \%$ \\
Ninguna & 28 & $34,32 \%$
\end{tabular}

Tabla 4. Valores de p calculado y sintomatología asociada con presencia de Candida albicans.

Posible asociación sintomatológica

$\begin{array}{ll}\text { respecto a presentar a Candida albicans } & \text { Valor } \mathrm{P}\end{array}$

Presencia de sangrado de encías

0,957

Presencia de dolor en las encías

0,005

Halitosis

0.356

Presencia de placa bacteriana

0,936

Presencia de sarro

0,297

Presencia de caries

0,717

Gingivitis

0,381

Periodontitis

Ningún síntoma

0,600 


\section{DISCUSIÓN DE RESULTADOS}

Teniendo en cuenta los resultado de las pruebas realizadas para la tipificación de Candida albicans, se identificó en el 67,7\%(67/99) de las muestras examinadas, en la evaluación de sensibilidad y/o resistencia se pudo evidenciar que los enjuagues codificados como E-1, E-2, E-3, E-6 y E-7 las cepas de Candida albicans aisladas presentaron resistencia al $50 \%$ de estos, no obstante en es su formulación indican poseer agentes antibacteriales y antifúngicos, en tanto que para los enjuagues los denominados E-4, E-5, E-8, E-9 y E-10, se apreció halo de inhibición, indicando ello la sensibilidad a dichos enjuagues.

Para la evaluación de las variables e identificar las posibles asociaciones, se halló significancia estadística con valor de p calculado de 0,005 para dolor en las encías y presencia de Candida albicans.

En cuanto a hábitos se identificó que: el 94\%(63/67) manifiesta tener dietas ricas en carbohidratos, $68,6 \%(46 / 67)$ consumo diario de golosinas y el $83,6 \%(56 / 67)$ mantener buenas condiciones de higiene oral. Al confrontar los resultados del presente estudio con lo reportado por Duque et al 2012 quienes manifiestan que los altos niveles de azúcar en la saliva favorecen el desarrollo de las levaduras del género Candida colonizando la cavidad oral (7); siendo concordante esta aseveración con lo hallado en el presente estudio. Entre las principales características de Candida albicans se destaca ser microbiota natural de la mucosa oral tanto en pacientes sanos como enfermos, sin causar sintomatología clínica (6). Según Carranza en el 2010 uno de los principales factores relacionados con la manifestaciones clínicas de Candida albicans es cuando se da una condición de menor respuesta del huésped, como se presenta en pacientes debilitados o que se hallan recibiendo tratamiento inmunosupresor, lo cual demuestra que la incidencia de la infección por candidiasis aumenta en forma progresiva en relación con la disminución de la capacidad inmune (6).

Otros autores como Dávila y Gil en el 2011, argumentan que las manifestaciones orales tienen importancia para la progresión de infecciones en pacientes pediátricos, en el estudio realizado por estos se aprecia un porcentaje significativo de presencia de caries en el 45,9\% de la población evaluada y una prevalencia de candidiasis oral del $73 \%$ (8). Al comparar con el presente estudio, se evidencia similitud en donde la presencia de caries fue del $35,82 \%$ y de candidiasis oral del $67,7 \%$, respectivamente, lo que permite inferir la relación que la presencia de alguna afección oral como lo es presentar piezas dentales cariadas favorece la aparición de otro tipo de afecciones orales como es dolor de encías, sangrado y cuadros de gingivitis ocasionado por Candida albicans (9).

De igual manera es de destacar que el 34,32\%(23/67) de los participantes en el estudio manifestaron no presentar ningún tipo de sintomatología, a pesar de identificarse el agente etiológico, lo que es atribuible al consumo de dietas ricas en carbohidratos y golosinas quienes favorecen la presencia Candida albicans, máxime si este agente etiológico es un habitante natural y hace parte de la microbiota de la cavidad oral.

\section{CONCLUSIONES}

En el presente estudio se puede concluir que en la población infantil en edad pre escolar y escolar del área urbana del municipio de Chaguaní Cundinamarca Colombia es prevalente Candida albicans en el cual se ha1ló un valor porcentual del $67,7 \%$.

La variable de dolor en las encías esta posiblemente asociada con la presencia de Candidiasis oral en la población infantil en edad preescolar y escolar, al hallarse significancia estadística para el valor de $\mathrm{p}$ calculado de 0,005 . De igual manera el consumo de dietas ricas en carbohidratos y golosinas puede favorecer la proliferación de Candida albicans en la cavidad oral y máxime que este hace parte de la microbiota natural de la cavidad oral.

\section{CONFLICTO DE INTERÉS}

Los autores declaramos el no presentar conflicto de intereses en la presente investigación.

\section{REFERENCIAS}

1. Pineda J., Cortés A., Urribarren T., Castañón L. Candidiosis vaginal. Primera parte: Revisión de la clínica, epidemiología y situación de México. Artículo de revisión. Universidad Nacional Autónoma de México. Revista Médica de Risaralda 2015; 21 (1): 58-63.

2. Atalaya R., Morales L. Prevalencia de candidiasis bucal en pacientes de la tercera edad que asisten a consulta médica al "hospital Jaime Mendoza" sucre, enero - agosto del 2009. Universidad Mayor, Real y Pontificia de San Francisco Xavier de Chuquisaca. Sucre - Bolivia. 2014. 298 - 331. Disponible en: http://www.ecorfan.org/bolivia/series/Topicos\%20 Selectos\%20de\%20Quimica_I/Articulo\%207.pdf

3. Valera Y., Herrera N., Carrero S., Díaz C., Correa 
M., Salazar O. Especies de Candida colonizantes de cavidad oral en pacientes pediátricos oncológicos hospitalizados en el IAHULA, Mérida, Venezuela. Universidad de Los Andes. Revista de la sociedad Venezolana de Microbiología 2014; 34: 22-26.

4. Gallón J. Cambios morfológicos e inhibición del crecimiento de Candida albicans, en presencia de una solución de sulfato de zinc. Tesis de maestría. Pontificia Universidad Javeriana. Facultad de Ciencias Básicas. Disponible en: http://repository.javeriana.edu.co/handle/10554/3307

5. López C., Giro L., Ramos L., Ramadán S., Bulacio L. Comparación de diferentes métodos para la identificación de especies del género Candida. Centro de Referencia en Micología (CEREMIC). Revista Argentina de Microbiología 2005; 37: 16-21.

6. López L., Cedeño F. Candidiasis bucal como infección micótica oportunista que afecta a los pacientes VIH/SIDA (Trabajo de grado). Universidad de Guayaquil. 2014. 7-41. Disponible en: http://repositorio. ug.edu.ec/handle/redug/6204

7. Duque C., Correa E., Rendón J., Bedoya J., Hernández O. Frecuencia de portadores de Candida sp en cavidad oral de pacientes diabéticos de Medellín. Institución Universitaria Colegio Mayor de Antioquia. NOVA. Publicación Científica en Ciencias Biomédicas. 2012; 10 (17): 33 - 37.

8. Dávila M., Gil M. Manifestaciones orales y caries dental en niños expuestos al virus de inmunodeficiencia humana. Universidad Centrooccidental Lisando Alvarado. Barquisimeto, Venezuela. Revista salud pública. 2011; 13 (5): 833-843.

9. De la Rosa E., Miramontes M., Sánchez L., Mondragón A. Colonización e infección bucal por Candida sp en pacientes diabéticos y no diabéticos con enfermedad renal crónica en diálisis. Revista Nefrología 2013; 33 (6): 764-770. doi:10.3265/Nefrología. pre2013.Aug. 11790 .

Fecha de recepción: 23/09/15

Fecha de aprobación: 07/10/15

Correspondencia: Andrea Milena Guatibonza

Email: amguatibonzac@gmail.com 